\title{
A Genetic Fusion between Sm14 and CTB does not Reduce Schistosoma mansoni Worm Burden on Intranasally Immunized BALB/c Mice
}

\author{
Henrique Roman Ramos ${ }^{1,2}$, Patricia Aoki Miyasato ${ }^{3}$, Celso Raul Romero Ramos ${ }^{4}$, Ana Paula de Mattos Arêas ${ }^{5}$, Toshie Kawano ${ }^{3}$ and Paulo Lee Ho Ra $^{1, *}$ \\ ${ }^{1}$ Centro de Biotecnologia, Instituto Butantan. Av. Vital Brasil, 1500 São Paulo SP, Brazil 05503-900 \\ ${ }^{2}$ Departamento de Bioquímica, Instituto de Química, Universidade de São Paulo. Av. Prof. Lineu Prestes, 748 São Paulo SP, Brazil 05513-970 \\ ${ }^{3}$ Laboratório de Parasitologia, Instituto Butantan. Av. Vital Brasil, 1500 São Paulo SP, Brazil 05503-900 \\ ${ }^{4}$ Departamento de Helmintologia, FIOCRUZ. Av. Brasil, 4635 Rio de Janeiro RJ, Brasil 21040-900 \\ ${ }^{5}$ Universidade Federal do ABC. Rua Santa Adélia, 166 Santo André SP, Brasil 09210-170
}

\begin{abstract}
Developing a vaccine against schistosomiasis would be an important advance on the control of this chronic and debilitating disease that afflicts millions of people worldwide. Herein we describe the use of the non-toxic B subunit of cholera toxin (CTB) genetically fused to Sm14 - a fatty-acid binding protein from Schistosoma mansoni - as an attempt to elicit a mucosal immune response against the lung stage of this parasite by intranasal immunization. Recombinant proteins were expressed on a prokaryotic system, purified by affinity chromatography and both immunochemically and spectroscopically characterized. Intranasal immunization experiments were performed on BALB/c mice and vaccine efficacy was assessed analyzing the worm-burden after challenge infection with $S$. mansoni cercariae. The results demonstrate that $\mathrm{Sm} 14$ itself was not able to reduce the worm burden on intranasally vaccinated animals. The presence of CTB - either in intranasal coadministration with or genetically fused to Sm14 - did not significantly improve the protective response of Sm14 as a worm burden reduction of only $20 \%$ could be observed. In addition to that, however, CTB demonstrated a clear anti inflammatory effect on the liver of immunized mice, which displayed hepatic granulomas around trapped eggs $15 \%$ smaller than control groups, indicating that CTB displays an immunomodulatory effect on the inflammatory responses induced by the parasite egg toxins.
\end{abstract}

\section{Introduction}

Schistosomiasis is a life threatening disease caused by blood flukes from the genus Schistosoma and despite effective and low cost chemotherapy is currently available, approximately 200 million people worldwide are infected with this parasite and other 600 million people are at risk of being infected [1]. Furthermore, failure in treatment with praziquantel has been reported recently indicating the development of resistant parasites [2]. As a result, developing of a vaccine would be an important advance on the control of this disease.

It is known that schistosomes are unable to replicate within the vertebrate host, this means that a vaccine, although desirable, does not need to have a sterilizing protection to provide a benefit. In fact, the World Health Organization (WHO) established that a vaccine that promotes, at least, a $40 \%$ reduction on worm burden would cause a significant impact on the global status of schistosomiasis. $\mathrm{Sm} 14$, a fatty-acid binding protein (FABP) from $S$. mansoni and one of the six vaccine candidates selected by the WHO for clinical trials, has been shown to reduce the worm burden in immunized mice [3]. Likewise, the elucidation of its biological and biochemical properties [4-6] led this antigen to be of particular interest of different research groups, being tested in different kinds of antischistosomiasis vaccine formulations [7-11].

Herein we describe an attempt to develop a vaccine against $S$. mansoni comprised by a genetic fusion between $\mathrm{Sm} 14$ and the nontoxic B subunit of cholera toxin (CTB), a molecule that has being used as mucosal adjuvant [12]. A robust mucosal immune response would be an interesting strategy to target the lung stage of $S$. mansoni. Indeed, CTB proved to elicit an adjuvant effect when used together with the $28 \mathrm{kDa}$ glutathione-S-transferase (Sm28GST) antigen from $S$. mansoni $[13,14]$. Biochemical characterizations were performed on the rCTB-Sm14 fusion protein in order to establish its stability and biological functionality. The efficacy of this vaccine was analyzed in terms of worm burden reduction in comparison with control groups. Furthermore, the hepatic granulomatous reactions around trapped eggs within the liver of infected mice had their areas measured and the effects of this vaccine on these inflammatory loci were also recorded.

\section{Materials and Methods \\ rCTB and rSm14 expression systems}

The individual cDNAs coding for the proteins $\mathrm{rCTB}[15]$ and $\mathrm{Sm} 14$ [6] were already cloned on the pAE plasmid [16], designed for highlevel prokaryotic expression of recombinant proteins with a minimal $\mathrm{N}$-terminal His6 tag controlled by the strong bacteriophage $\mathrm{T} 7$ promoter.

\section{Cloning of CTB-Sm14 fusion construct}

For the construction of the CTB-Sm14 fusion construct, the complete sm14 cDNA sequence was PCR amplified from its pAE plasmid template [6]. For this reaction, a forward primer containing

*Corresponding author: Paulo Lee Ho, Laboratório de Biotecnologia Molecula I, Centro de Biotecnologia, Instituto Butantan. Av. Vital Brasil, 1500 São Paulo SP, Brazil 05503-900, Tel: +55 11 3726-7222 ext. 2244; Fax: +55 11 3726-1505; E-mail: hoplee@butantan.gov.br

Received December 17, 2010; Accepted December 29, 2010; Published December 30, 2010

Citation: Ramos HR, Miyasato PA, Ramos CRR, de Mattos Arêas AP, Kawano T et al. (2010) A Genetic Fusion between Sm14 and CTB does not Reduce Schistosoma mansoni Worm Burden on Intranasally Immunized BALB/c Mice. J Vaccines Vaccin 1: 111. doi:10.4172/2157-7560.1000111

Copyright: (c) 2010 Ramos HR, et al. This is an open-access article distributed under the terms of the Creative Commons Attribution License, which permits unrestricted use, distribution, and reproduction in any medium, provided the original author and source are credited. 
Citation: Ramos HR, Miyasato PA, Ramos CRR, de Mattos Arêas AP, Kawano T et al. (2010) A Genetic Fusion between Sm14 and CTB does not Reduce Schistosoma mansoni Worm Burden on Intranasally Immunized BALB/c Mice. J Vaccines Vaccin 1: 111. doi:10.4172/21577560.1000111

Page 2 of 6

a Mlul restriction site was designed and an oligonucleotide complementary to the T7 terminator region was used as reverse primer. The amplicons were then double digested with Mlul and HindIII restriction enzymes and cloned into the pAE-ctb plasmid [15], at the 3' region and in frame with of the ctb DNA sequence.

\section{Expression and purification of recombinant proteins}

rSm14 and rCTB expression and purification: Expression and purification of $\mathrm{rSm} 14$ and $\mathrm{rCTB}$ were performed as previously described $[6,15]$.

rCTB-Sm14 expression and purification: The pAE-ctb-sm14 plasmid was transformed in chemically competent Escherichia coli cells, which were grown on Luria-Bertani medium and induced for $3 \mathrm{~h}$ by the addition of $1 \mathrm{mM}$ isopropyl-1-thio- $\beta$-D-galactopyranoside when 0.6 of optical density at $600 \mathrm{~nm}$ was achieved. After the induction period, the cells were collected and mechanically lysed by French Press (Thermo Fisher Scientific Inc.) and the inclusion bodies containing the recombinant His6 tag protein were isolated from bacterial lysates and solubilized with $20 \mathrm{~mL}$ of solubilization buffer (8 M urea, $50 \mathrm{mM}$ Tris- $\mathrm{Cl}, 5 \mathrm{mM} \beta$-mercaptoethanol, $\mathrm{pH}$ 8.0). The material was then slowly diluted 200 times in refolding buffer $(5 \mathrm{mM}$ imidazole, $500 \mathrm{mM} \mathrm{NaCl}, 50 \mathrm{mM}$ Tris-Cl, $100 \mathrm{mM} \mathrm{D(+)-Galactose,}$ $\mathrm{pH}$ 8.0).

Refolded protein solution was adsorbed on a $5 \mathrm{~mL}$ nickel sepharose affinity column $(10 \mathrm{~mm}$ diameter) equilibrated with 5 column volumes $(\mathrm{CV})$ of refolding buffer. The resin was washed with $5 \mathrm{CV}$ of washing buffer $(40 \mathrm{mM}$ imidazole, $500 \mathrm{mM} \mathrm{NaCl}, 50 \mathrm{mM}$ Tris$\mathrm{HCl}, 100 \mathrm{mM} \mathrm{D}(+)$-Galactose, $\mathrm{pH} 8.0$ ) and the protein was eluted with $5 \mathrm{CV}$ of elution buffer $(1 \mathrm{M}$ imidazole, $500 \mathrm{mM} \mathrm{NaCl}, 50 \mathrm{mM}$ Tris$\mathrm{HCl}, 100 \mathrm{mM} \mathrm{D}(+)$-Galactose, pH8.0). After elution, imidazole was removed from the solution by buffer exchange using a $30 \mathrm{kDa}$ cutoff centriprep system (Millipore Co.). Final buffer solution (BS) was 150 $\mathrm{mM} \mathrm{NaCl}, 50 \mathrm{mM}$ Tris-Cl, $100 \mathrm{mM} \mathrm{D}(+)$-Galactose and $\mathrm{pH}$ adjusted to 8.0 .

\section{rCTB-Sm14 stability improvement}

For protein stability studies, proteins were kept either in BS with or without $100 \mathrm{mM}$ galactose for up to 3 months at $4^{\circ} \mathrm{C},-20^{\circ} \mathrm{C}$ or lyophilized. Results were evaluated by non reducing SDS-PAGE [17].

\section{Western-blot analysis}

Nitrocellulose membranes, after protein transfer from $12 \%$ SDSPAGE [17], were blocked with $5 \%(\mathrm{~m} / \mathrm{V})$ non-fat milk in $0.05 \%$ Tween 20/phosphate buffered saline (PBS-T). Membranes were washed three times for 10 min with PBS-T, and further incubated with a proper dilution of mouse polyclonal specific antibodies in 5\% non-fat milkPBS-T, for $1 \mathrm{~h}$, followed by PBS-T washing as described above. Membranes were then incubated with a proper dilution of anti-mouse IgG peroxidase conjugate in $5 \%$ non-fat milk-PBS-T, washed with the same procedure, and revealed with ECL reagent (GE Healthcare).

\section{SDS-PAGE of CTB-Sm14 and GM1-ELISA}

The ability of the CTB-Sm 14 fusion protein to fold into pentamers was analyzed by a $12 \%$ SDS-PAGE [17].For this, samples were not boiled and a sample buffer that did not contain $\beta$ - mercaptoethanol was used [15].

The GM1-ELISA protocol was adapted from a reference published elsewhere [18]. Briefly, microtiter 96-well plates were coated with $10 \mu \mathrm{g} \mathrm{ml}-1 \mathrm{GM} 1$ ganglioside in $\mathrm{PBS}, \mathrm{pH} 7.2$, at $37^{\circ} \mathrm{C}$ for $16 \mathrm{~h}$. After three PBS-T washes, the plates were blocked by incubation with a $1 \%(\mathrm{~m} / \mathrm{V})$ BSA-PBS-T solution for $30 \mathrm{~min}$ at room temperature. The recombinant proteins were then serial diluted, from $300 \mathrm{mM}$ to 300 $\mathrm{nM}$, in $1 \% \mathrm{BSA}-\mathrm{PBS}-\mathrm{T}(\mathrm{m} / \mathrm{V})$ and incubated for $2 \mathrm{~h}$ at room temperature. Unbound proteins were removed from the plate by washing three times with PBS-T, and then a proper dilution of a specific polyclonal antibody was added to the plates and incubated for another hour at room temperature. After three PBS-T washes, a proper dilution of peroxidase-conjugated goat anti-mouse $\operatorname{IgG}$ (Sigma) was added to the plate and incubated for $1 \mathrm{~h}$ at room temperature. Unbound antibodies were removed by washing as described above with PBS-T and plates were revealed by the addition of $8 \mathrm{mg}$ o-phenylenediamine (OPD) in

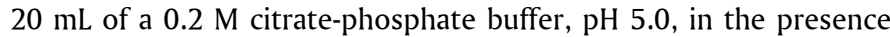
of $10 \mu \mathrm{L} \mathrm{H} 2 \mathrm{O} 2$. The reaction was stopped by adding $4 \mathrm{M} \mathrm{H}_{2} \mathrm{SO}_{4}$. The absorbance was measured at $492 \mathrm{~nm}$.

\section{Fatty-acid binding activity of rCTB-Sm 14}

The fatty-acid binding ability of recombinant proteins was determined by fluorescence spectroscopy using the fluorescent fatty-acid analogue 11-(dansylamino) undecanoic acid (DAUDA) (Molecular Probes). The excitation wavelength used for DAUDA was $345 \mathrm{~nm}$ and emission spectra were registered from $360 \mathrm{~nm}$ to $670 \mathrm{~nm}$. The protein and DAUDA concentrations were $2 \mu \mathrm{M}$, in PBS $\mathrm{pH} 7.4$ and measurements were carried out at $20^{\circ} \mathrm{C}$ using a SLMAMINCO-Bowman Series II Luminescence Spectrometer (Spectronic Instruments) with $1 \mathrm{ml}$ samples in a quartz cell (Ramos et al., 2003).

\section{Circular Dichroism (CD) measurements}

$\mathrm{CD}$ measurements were carried out at $20^{\circ} \mathrm{C}$ on a Jasco J-810 Spectropolarimeter equipped with a Peltier unit for temperature control. A Far-UV CD spectrum was acquired using a $1 \mathrm{~mm}$ path length cell at $0.5 \mathrm{~nm}$ intervals over the wavelength range from 190 to $260 \mathrm{~nm}$. Five scans were averaged for each sample and subtracted from the blank average spectra. The protein concentration was kept at $10 \mu \mathrm{M}$ in $20 \mathrm{mM}$ sodium-phosphate buffer $\mathrm{pH}$ 7.4.

\section{Animal handling and immunization regimens}

Immunization regimens and Schistosoma mansoni challenge: Four consecutive doses of antigen (Table 1) were given intranasally with 7 days interval to 7 weeks old females BALB/c mice, weighting around 18 to $20 \mathrm{~g}$ and divided in groups of 10 animals. Challenge was performed 2 weeks after the last dose. For this, animals were depilated on the abdominal region, anesthetized with $10 \mathrm{mg} \mathrm{Kg}-1$ Xylazine and $100 \mathrm{mg} \mathrm{Kg}-1 \mathrm{Ketamine}$ and had their abdominal skin exposed for 30 minutes to a $1 \mathrm{~mL}$ solution containing 100 Schistosoma mansoni cercariae (BH strain). Overall protection was calculated by the formula $[(C-V) \times C-1] \times 100$, where $C$ is the average number of worms recovered from control animals and $\mathrm{V}$ is the average number of worms recovered from vaccinated animals.

Animal handling protocol was approved by the Instituto Butantan`s ethics committee (São Paulo, Brazil).

\section{Animal bleeding and vaginal wash}

Animals had their bloods collected by the retro-orbital plexus/ sinus with a glass Pasteur pipette. Three bleedings were made, being the first one performed 7 days after the last dose; the second one performed at the moment of the challenge and the last bleeding was performed just before the perfusion. A vaginal wash, with $50 \mu \mathrm{L} 0.9 \%$ saline solution, was performed one week prior to the challenge in order to evaluate the production of secretory IgA. 
Citation: Ramos HR, Miyasato PA, Ramos CRR, de Mattos Arêas AP, Kawano T et al. (2010) A Genetic Fusion between Sm14 and CTB does not Reduce Schistosoma mansoni Worm Burden on Intranasally Immunized BALB/c Mice. J Vaccines Vaccin 1: 111. doi:10.4172/21577560.1000111

Page 3 of 6

\section{ELISA}

Microtiter 96-well plates were coated with $10 \mu \mathrm{g}$ ml- 1 of $\mathrm{rSm} 14$ or rCTB in Carbonate- Bicarbonate Buffer, pH 9.6 for $16 \mathrm{~h}$ at $4^{\circ} \mathrm{C}$. After three washes with PBS-T, plates were blocked with $5 \%$ non-fat milk/ PBS-T $(\mathrm{m} / \mathrm{V})$ at $37^{\circ} \mathrm{C}$ for $1 \mathrm{~h}$. Serial dilutions of each serum in PBS-T were added to the wells and incubated for $1 \mathrm{~h}$ at $37^{\circ} \mathrm{C}$. Bound antibodies were detected by a commercial peroxidaseconjugated anti-mouse $\lg G, \lg G_{1}$ or $\lg G_{2 a}$ in an appropriate dilution. The addition of OPD and the following steps were performed as previously described in GM1-ELISA.

\section{Histopathology}

Livers of vaccinated animals were removed at the moment of perfusion and fixed in $4 \%$ paraformaldehyde in PBS. From each vaccinated group, three animals were selected according to their level of infection defined by the number of worms recovered (low, average and high worm burdens). Histological sections were performed using microtome at $6 \mu \mathrm{m}$ and stained in a slide with hematoxilin-eosin (HE).

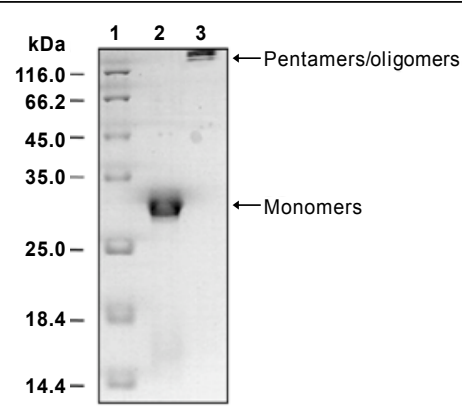

Figure 1: SDS-PAGE analysis of purified recombinant CTB-Sm14 and its ability to fold into pentameric/oligomeric structures. Lane 1. Molecular Mass Marker Lane 2. rCTB-Sm14 in the presence of $\beta$-mercapthoethanol and heated at 96oC. Lane 3. rCTB-Sm14 in non-reducing conditions and not heated.

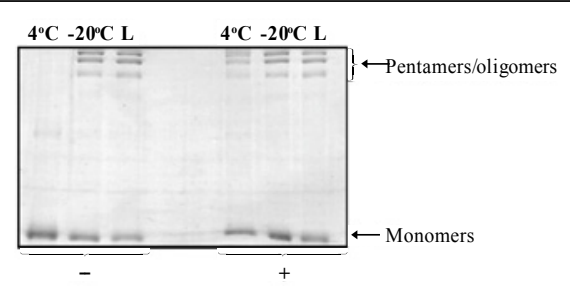

Figure 2: SDS-PAGE in non reducing conditions displaying the increase of rCTB-Sm14 stability in the presence of $D(+)$-Galactose after 3 months. +: presence of $D(+)$-Galactose; - : absence of $D(+)$-Galactose.

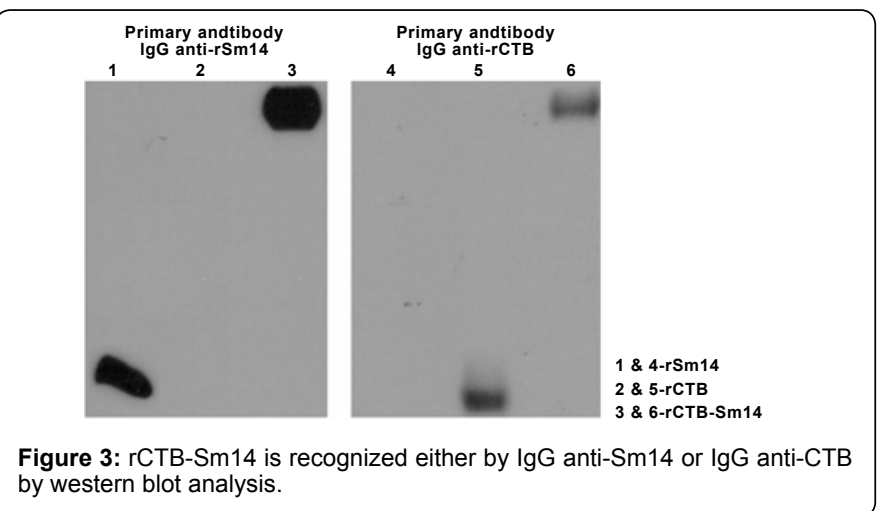

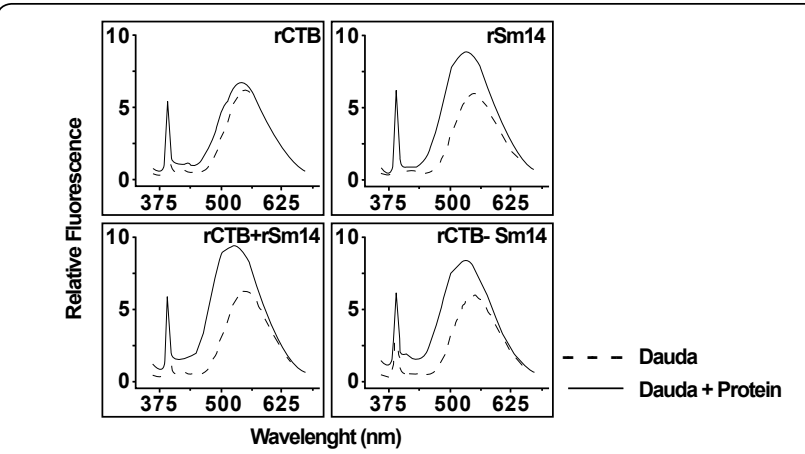

Figure 4: Fatty-acid binding by $\mathrm{rSm} 14$ and rCTB-Sm14. The blue-shift in DAUDA fluorescence emission indicates the ability of rSm14 and also rCTBSm14 proteins to bind fatty-acids.

70 granulomas with a single well-defined egg were randomly chosen and had their individual areas determined using a computer-assisted image analysis device (AxioVision Rel. 4.6, Carl Zeiss, Inc.)

\section{Statistical analysis}

Statistical analysis was performed with non-paired Student's t-test, with results with statistical significance when $p<0.05$.

\section{Results}

\section{Expression and purification of recombinant CTB-Sm14 fusion protein}

Twenty five milligrams of purified protein per liter of induced culture were obtained and SDSPAGE analysis of eluted fractions from immobilized metal ion affinity chromatography allowed the observation of a single band of $30 \mathrm{kDa}$ corresponding to the rCTBSm14 monomers under reduced conditions. In non-reduced and non-boiled samples, we can observe that the proteins were able to achieve quaternary pentameric/oligomeric structures (Figure 1).

\section{Stability improvement of $\mathrm{rCTB}-\mathrm{Sm} 14$ by $\mathrm{D}(+)$-galactose}

It is known that the GM1-ganglioside has on its structure two galactose residues and one Nacetyl- galactosamine residue. The terminal galactose residue displays an important function in CTB binding as determined by crystallographic studies [19]. Based on the fact that proteins should become more stable when its ligand is present, we decided to check whether the presence of galactose on CTB-Sm14 solution would improve protein stability. Indeed, this carbohydrate increased significantly the recombinant protein stability (Figure 2). Non-reducing SDS-PAGE analysis showed that the proteins, when stored in the presence of galactose, even after 3 months at $4 \mathrm{C}$, conserved their pentameric/oligomeric structure, in contrast to a sample without galactose. On the other hand, no visible difference could be observed between samples stored at -20C and/or lyophilized. For these reasons we kept all the CTB-Sm 14 at $-20^{\circ} \mathrm{C}$ in the presence of $100 \mathrm{mM}$ galactose.

\section{The rCTB-Sm14 protein is recognized either by anti-Sm14 or anti-CTB antibodies}

Western blot analysis clearly demonstrates that the recombinant fusion protein is detected by both anti-Sm14 and anti-CTB IgGs, indicating the presence of these two distinguishable fragments in a same protein (Figure 3).

\section{Fatty-acid binding ability of Sm14 recombinant proteins}

To ensure the functionality of the fatty-acid binding portion of 
Citation: Ramos HR, Miyasato PA, Ramos CRR, de Mattos Arêas AP, Kawano T et al. (2010) A Genetic Fusion between Sm14 and CTB does not Reduce Schistosoma mansoni Worm Burden on Intranasally Immunized BALB/c Mice. J Vaccines Vaccin 1: 111. doi:10.4172/21577560.1000111

Page 4 of 6

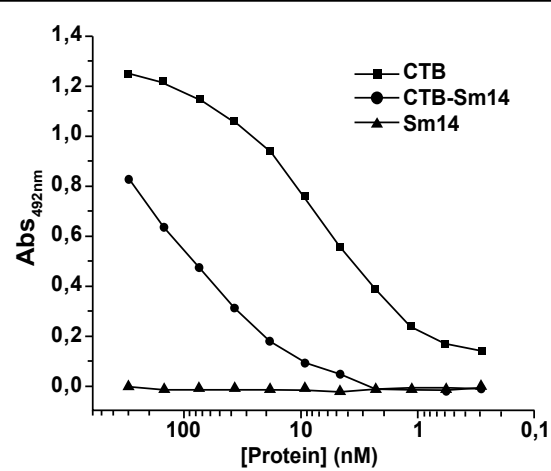

Figure 5: GM1 binding activity by GM1-ELISA assay. In order to verify the ability of the protein pentamers to bind GM1 gangliosides, a GM1-ELISA was performed using recombinant CTB-Sm14, CTB or Sm14. The ELISA was performed by coating a $96-$ well plate with GM1.

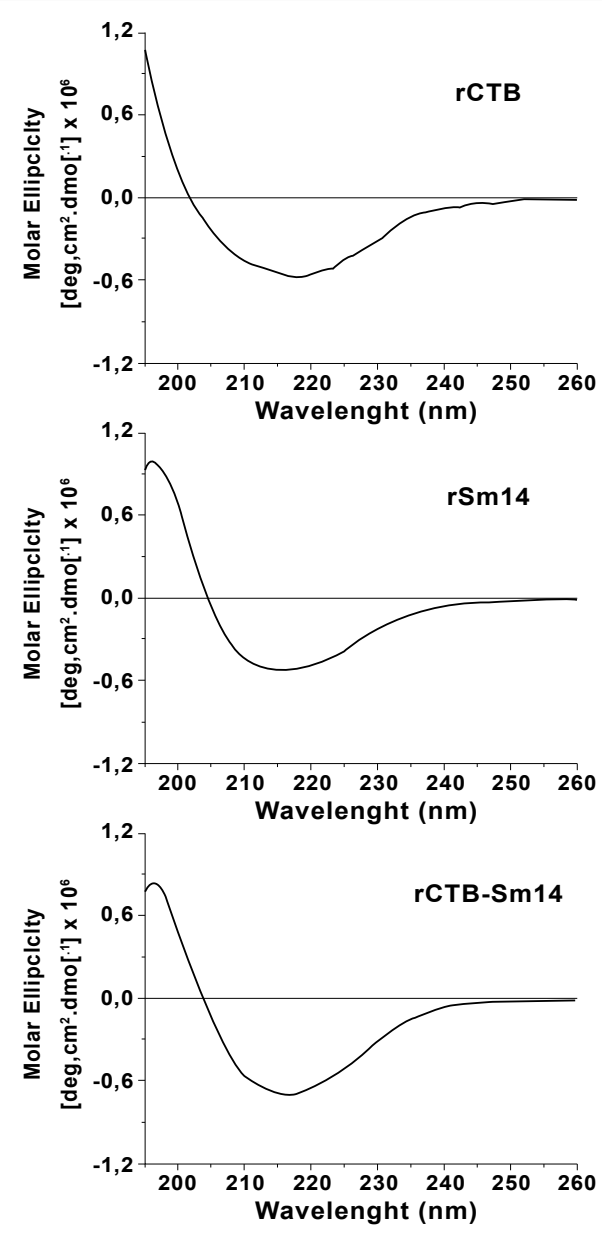

Figure 6: Secondary structures of recombinant proteins by circular dichroism.

the rCTB-Sm14 fusion protein, we used the fluorescent fatty-acid analogue DAUDA to monitor fluorescence shifts that are caused by the internalization of this probe onto a more hydrophobic milieu. The blue shift of DAUDA fluorescence maximum from $550 \mathrm{~nm}$ to 532 $533 \mathrm{~nm}$ for rSm14 and rCTB-Sm14 (Figure 4) and the concomitant increase of its fluorescence emission (both indicative of the entry of DAUDA into an apolar environment) confirmed the binding of the fluorescent fatty acid not only by the $\mathrm{rSm} 14$ protein but also by the recombinant fusion protein (rCTB-Sm14). As expected, figure 4 also shows that the recombinant CTB protein alone, did not significantly bind DAUDA. However a blue-shift was observed when rSm14 was added to the rCTB containing solution ( $\mathrm{rCTB}+\mathrm{rSm} 14)$. This demonstrates that fluorescence displacement is specifically related to the $\mathrm{rSm} 14$ protein and that CTB does not significantly interfere with the DAUDA binding to $S \mathrm{~m} 14$, showing the functionality of $\mathrm{Sm} 14$ portion in the fusion CTB-Sm14 protein.

\section{GM1 ganglioside binding by rCTB-Sm 14}

To confirm the ability of the rCTB-Sm14 pentamers/oligomers to bind to its cellular ganglioside receptor GM1, a GM1-ELISA was performed. Recombinant CTB and CTB-Sm14 were able to bind GM1 in a dose-dependent manner. However it is clear that the presence of five Sm14 molecules in the structure imposed some interference with the binding capacity of CTB to GM1 as it showed a lower affinity than rCTB itself (Figure 5). Actually, the binding potential of CTB to GM1 has already been described elsewhere to be somewhat lower when fused to other proteins $[20,21]$.

\section{Secondary structure analysis of the recombinant proteins}

$\mathrm{CD}$ analysis of recombinant proteins allowed us to infer that all molecules, as expected, displayed a regular secondary structure enriched in $\beta$ sheets after the purification process (Figure 6).

\section{Vaccination experiments}

Intranasal immunization was performed as an attempt to elicit both systemic and mucosal immune response in the animals. Table 1 shows the experimental groups used in the intranasal vaccination experiments. Total $\operatorname{IgG}$ anti-Sm 14 antibodies titers from sera of intranasally vaccinated animals could only be detected when CTB was present, being the high levels of these immunoglobulins present on those animals that received the recombinant fusion protein. Likewise, detectable levels of IgA anti-Sm14 antibodies in mucosal secretion from vaccinated animals were only observed in mice that received the recombinant fusion protein (Table 2).

However, no desirable protection levels could be observed in any vaccinated group. Furthermore, only those animals that received

\begin{tabular}{|l|l|}
\hline Group & Dose \\
\hline Saline & - \\
\hline CTB & $4 \mu \mathrm{g}$ rCTB \\
\hline Sm14 & $4 \mu \mathrm{rSm} 14$ \\
\hline CTB + Sm14 & $4 \mu \mathrm{rCTB}+4 \mu \mathrm{g} \mathrm{rSm} 14$ \\
\hline CTB-Sm14 & $8 \mu \mathrm{g}$ rCTB-Sm14 \\
\hline
\end{tabular}

Table 1: Vaccination groups with respective antigens and doses administered to animals.

\begin{tabular}{|l|l|l|l|l|}
\hline & \multicolumn{2}{|l|}{ IgG } & IgA \\
\hline Group & 1st Bleeding & 2nd Bleeding & 3rd Bleeding $^{b}$ & Vaginal Wash \\
\hline Saline & $<20$ & $<20$ & $<20$ & $<4$ \\
\hline CTB & 20 & $<20$ & $<20$ & $<4$ \\
\hline Sm14 & $<20$ & $<20$ & $<20$ & $<4$ \\
\hline CTB + Sm14 & 20 & 80 & $<20$ & $<4$ \\
\hline CTB-Sm14 & 640 & 1280 & 80 & 20 \\
\hline
\end{tabular}

At the moment of perusion

Table 2: Total serum IgG and mucosal IgA titers on vaccinated animals.

\begin{tabular}{|l|l|l|l|}
\hline Group & Worm Burden \pm Standard Deviation & Protection $(\%)$ & $P$ value \\
\hline Saline & $42.53 \pm 11.86$ & - & - \\
\hline CTB & $45.69 \pm 13.77$ & - & - \\
\hline Sm14 & $49.18 \pm 13.00$ & - & - \\
\hline CTB + Sm14 & $35.65 \pm 9.43$ & $21.98^{\mathrm{a}}$ & 0.020 \\
\hline CTB-Sm14 & $36.87 \pm 5.73$ & $19.31^{\mathrm{a}}$ & 0.029 \\
\hline
\end{tabular}

*Mean of two independent experiments

Table 3: Worm burden and protection observed on vaccinated animals. 
Citation: Ramos HR, Miyasato PA, Ramos CRR, de Mattos Arêas AP, Kawano T et al. (2010) A Genetic Fusion between Sm14 and CTB does not Reduce Schistosoma mansoni Worm Burden on Intranasally Immunized BALB/c Mice. J Vaccines Vaccin 1: 111. doi:10.4172/21577560.1000111

Page 5 of 6

\begin{tabular}{|l|l|l|l|}
\hline Group & Average $\left(\times 10^{4}\right) \pm$ S.D. $\left(\times 10^{4}\right) \mu \mathrm{m}^{2^{*}}$ & Reduction $(\%)$ & $P$ value \\
\hline Saline & $10.32 \pm 4.12$ & - & - \\
\hline CTB & $8.89 \pm 3.84$ & - & - \\
\hline Sm14 & $9.99 \pm 3.82$ & - & - \\
\hline CTB + Sm14 & $7.44 \pm 2.71$ & $16.35^{\text {a }}$ & 0.01072 \\
\hline CTB-Sm14 & $7.60 \pm 2.79$ & $14.51^{\text {a }}$ & 0.04194 \\
\hline
\end{tabular}

*Mean of two independent experiments

aln comparison with Saline + CTB group

Table 4: Hepatic granuloma area size around trapped eggs on vaccinated animals.

rSm14 in coadministration with $\mathrm{rCTB}$ and those animals that received the rCTB-Sm 14 fusion protein displayed a discrete level of reduction (around 20\%) on worm burden (Table 3).

\section{Histopathology}

Histological analysis of hepatic tissues from animals intranasally immunized with $\mathrm{rSm} 14$ in coadministration with $\mathrm{rCTB}$ showed a reduction of $16.35 \%$ on the area of granulomatous reaction around trapped eggs. Similarly, the recombinant fusion protein reduced in $14.51 \%$ these inflammatory areas (Table 4 ).

\section{Discussion}

Since the very first results from mice immunized with attenuated Schistosoma mansoni cercariae [22], where high levels of protection were observed, the search for an anti-schistosomiasis vaccine has turned out to be a huge challenge as those results has revealed difficult to be reproduced using individual antigens, even in the presence of strong adjuvants.

The use of the fatty-acid binding protein from $S$. mansoni, dates from 1996, when it elicited $89 \%$ protection on vaccinated rabbits and $59.6 \%$ protection on Swiss mice [3]. Later on, Sm 14 would be expressed in a more feasible Escherichia coli system for large scale production and downstream processing and results were again promising as vaccinated animals showed a reduction of $43.9 \%$ in the worm burden [23], leading this antigen to be a subject of intense studies that resulted in its molecular and biochemical characterization $[5,6]$, in the resolution of its three dimensional structure $[4,24]$ and in different immunization experiments that would support Sm14's efficacy as a promising vaccine antigen candidate $[8,9,11,25]$. As a matter of fact, this molecule is already being tested either as a veterinary or as a human vaccine against fasciolosis and schistosomiasis, respectively [26].

Concerning the immune responses against Schistosoma mansoni in the attenuated cercariae model, it has been shown that optimally irradiated larvae undergo a delayed migration terminating in the lungs where the parasites die. Furthermore, this persistence in the lungs is crucial for the higher levels of resistance after challenge infection [27]. In addition to that, the recruitment of lymphocytes to the lung seems to be of great importance in generating a protective immunity [28]. These data strongly suggest the importance of the immune response elicited in the lungs and, as a result, we hypothesized that a vaccine that would induce an immune response in the mucosa-associated lymphoid tissue (MALT) might elicit a better result in vaccinated animals.

The use of СТВ as a mucosal adjuvant has been widely described in diverse kinds of vaccine formulations, against different microorganisms or to induce tolerance in autoimmune diseases [20,29-37] and showed positive results when administered together with Sm28GST [13,14,38,39]. Therefore, we decided to fuse CTB to Sm14 in order to evaluate its efficacy as an intranasal mucosal Sm14 based vaccine.
Different biochemical characterizations were performed on the recombinant proteins and the results clearly demonstrated that all the proteins were at least partially folded and functional. The adjuvanticity of CTB clearly induced the secretion of anti-Sm 14 IgC and IgA from vaccinated animals. The levels of antibodies, however, are barely detectable, what should explain the poor protection obtained on vaccinated animals. These data led us to think about the possibility of increasing the amount of antigen, but this would not be possible as higher doses of СТВ would elicit an unspecific immune response, limiting the amount of antigen to be used (unpublished results). On the other hand, it is important to emphasize that the hepatic granuloma area size on animals which received CTB, either in coadministration with or genetically fused to $\mathrm{Sm} 14$, was significantly lower, indicating that the use of CTB could be a way of reducing the morbidity caused by $S$. mansoni. Indeed, this was not the first time that a reduction on hepatic granuloma was observed; the chemicalconjugation of CTB with Schistosoma mansoni Glutathione S-Transferase (Sm28GST) had already shown a reduction on these inflammatory responses [13].

In conclusion, the data presented here showed that CTB can be used as a way of reducing the morbidity of schistosomiasis by affecting the hepatic granuloma area size, as observed and described in the previous results with Sm28GST $[13,14,38,39]$. Unfortunately, in our conditions, $\mathrm{Sm} 14$ did not induce considerable levels of protection by intranasal vaccination of the animals.

\section{Financial Support}

Fundação de Amparo à Pesquisa do Estado de São Paulo (FAPESP) Conselho Nacional de Desenvolvimento Científico e Tecnológico (CNPq) and Fundação Butantan

\section{References}

1. Chitsulo L, Engels D, Montresor A, Savioli L (2000) The global status of schistosomiasis and its control. Acta Trop 77: 41-51.

2. Doenhoff MJ, Kusel JR, Coles GC, Cioli D (2002) Resistance of Schistosoma mansoni to praziquantel: is there a problem? Trans R Soc Trop Med Hyg 96: 465-469.

3. Tendler M, Brito CA, Vilar MM, Serra-Freire N, Diogo CM et al. (1996) A Schistosoma mansoni fatty acid-binding protein, Sm14, is the potential basis of a dual-purpose antihelminth vaccine. Proc Natl Acad Sci U S A 93: 269-273.

4. Angelucci $F$, Johnson KA, Baiocco P, Miele AE, Brunori M, et al. (2004) Schistosoma mansoni fatty acid binding protein: specificity and functional control as revealed by crystallographic structure. Biochemistry 43: 1300013011.

5. Pertinhez TA, Sforça ML, Alves AC, Ramos CR, Ho PL, et al. (2004) $1 \mathrm{H}, 15 \mathrm{~N}$ and $13 \mathrm{C}$ resonance assignments of the apo Sm14-M20(C62V) protein, a mutant of Schistosoma mansoni Sm14. J Biomol NMR 29: 553-554.

6. Ramos CR, Figueredo RC, Pertinhez TA, Vilar MM, do Nascimento AL, et al (2003) Gene structure and M20T polymorphism of the Schistosoma manson Sm14 fatty acid-binding protein. Molecular, functioanl, and immunoprotection analysis. J Biol Chem 278: 12745-12751.

7. Abreu PA, Miyasato PA, Vilar MM, Dias WO, Ho PL, et al. (2004) Sm14 of Schistosoma mansoni in fusion with tetanus toxin fragment $\mathrm{C}$ induces immunoprotection against tetanus and schistosomiasis in mice. Infect Immun 72: 5931-5937.

8. Fonseca CT, Brito CF, Alves JB, Oliveira SC (2004) IL-12 enhances protective immunity in mice engendered by immunization with recombinant $14 \mathrm{kDa}$ Schistosoma mansoni fatty acid-binding protein through an IFN-gamma and TNF-alpha dependent pathway. Vaccine 22: 503-510.

9. Fonseca CT, Pacífico LG, Barsante MM, Rassi T, Cassali GD, et al. (2006) Coadministration of plasmid expressing IL-12 with $14-\mathrm{kDa}$ Schistosoma manson fatty acid-binding protein cDNA alters immune response profiles and fails to enhance protection induced by Sm14 DNA vaccine alone. Microbes Infect 8 : 2509-2516. 
Citation: Ramos HR, Miyasato PA, Ramos CRR, de Mattos Arêas AP, Kawano T et al. (2010) A Genetic Fusion between Sm14 and CTB does not Reduce Schistosoma mansoni Worm Burden on Intranasally Immunized BALB/c Mice. J Vaccines Vaccin 1: 111. doi:10.4172/21577560.1000111

Page 6 of 6

10. Pacheco LG, Zucconi E, Mati VL, Garcia RM, Miyoshi A, et al. (2005) Oral administration of a live Aro attenuated Salmonella vaccine strain expressing 14$\mathrm{kDa}$ Schistosoma mansoni fatty acid-binding protein induced partial protection against experimental schistosomiasis. Acta Trop 95: 132-142.

11. Varaldo PB, Leite LC, Dias WO, Miyaji EN, Torres FI, et al. (2004) Recombinant Mycobacterium bovis BCG expressing the Sm14 antigen of Schistosoma mansoni protects mice from cercarial challenge. Infect Immun 72: 3336-3343.

12. Holmgren J, Adamsson J, Anjuère F, Clemens J, Czerkinsky C, et al. (2005) Mucosal adjuvants and anti-infection and anti-immunopathology vaccines based on cholera toxin, cholera toxin B subunit and CpG DNA. Immunol Lett 97: 181-188.

13. Sun JB, Mielcarek N, Lakew M, Grzych JM, Capron A, et al. (1999) Intranasal administration of a Schistosoma mansoni glutathione S-transferasecholera toxoid conjugate vaccine evokes antiparasitic and antipathological immunity in mice. J Immunol 163: 1045-1052.

14. Lebens M, Sun JB, Sadeghi H, Bäckström M, Olsson I, et al. (2003) A mucosally administered recombinant fusion protein vaccine against schistosomiasis protecting against immunopathology and infection. Vaccine 21: 514-520.

15. Arêas AP, Oliveira ML, Ramos CR, Sbrogio-Almeida ME, Raw I, et al. (2002) Synthesis of cholera toxin B subunit gene: cloning and expression of a functional 6XHistagged protein in Escherichia coli. Protein Expr Purif 25: 481-487.

16. Ramos CR, Abreu PA, Nascimento AL, Ho PL (2004)A high-copy T7 Escherichia coli expression vector for the production of recombinant proteins with a minimal Nterminal His-tagged fusion peptide. Braz J Med Biol Res 37: 1103-1109.

17. Shapiro AL, Viñuela E, Maizel JV Jr (1967) Molecular weight estimation of polypeptide chains by electrophoresis in SDS-polyacrylamide gels. Biochem Biophys Res Commun 28: 815-820

18. Menezes CA, Amianti J, Harayama HS, Koga PC, Trabulsi LR, et al. (2002) Inhibition of Escherichia coli heat-labile enterotoxin by neoglycoprotein and anti-lectin antibodies which mimic GM1 receptor. FEMS Microbiol Lett 216: 6770 .

19. Merritt EA, Sarfaty S, van den Akker F, L'Hoir C, Martial JA, et al. (1994) Crystal structure of cholera toxin B-pentamer bound to receptor GM1 pentasaccharide. Protein Sci 3: 166-175

20. Bublin M, Hoflehner E, Wagner B, Radauer C, Wagner S, et al. (2007) Use of a genetic cholera toxin B subunit/allergen fusion molecule as mucosal delivery system with immunosuppressive activity against Th2 immune responses. Vaccine 25: 8395-8404

21. Liljeqvist S, Ståhl S, Andréoni C, Binz H, Uhlén M, et al. (1997) Fusions to the cholera toxin B subunit: influence on pentamerization and GM1 binding. $J$ Immunol Methods 210: 125-135.

22. Villella JB, Gomberg HJ, Gould SE (1961) Immunization to Schistosoma mansoni in mice inoculated with radiated cercariae. Science 134: 1073-1075.

23. Ramos CR, Vilar MM, Nascimento AL, Ho PL, Thaumaturgo N, et al. (2001) r-Sm14 - pRSETA efficacy in experimental animals. Mem Inst Oswaldo Cruz 96 Suppl: 131-135.

24. Ramos CR, Spisni A, Oyama S Jr, Sforça ML, Ramos HR, et al. (2009) Stability improvement of the fatty acid binding protein $\mathrm{Sm} 14$ from S. mansoni by Cys replacement: structural and functional characterization of a vaccine candidate. Biochim Biophys Acta 1794: 655-662.

25. Vilar MM, Barrientos F, Almeida M, Thaumaturgo N, Simpson A, et al. (2003) An experimental bivalent peptide vaccine against schistosomiasis and fascioliasis Vaccine 22: 137-144

26. Tendler M, Simpson AJ (2008) The biotechnology-value chain: development of $\mathrm{Sm} 14$ as a schistosomiasis vaccine. Acta Trop 108: 263-266.

27. Mountford AP, Coulson PS, Wilson RA (1988) Antigen localization and the induction of resistance in mice vaccinated with irradiated cercariae of Schistosoma mansoni. Parasitology 97: 11-25.

28. Coulson PS, Wilson RA (1997) Recruitment of lymphocytes to the lung through vaccination enhances the immunity of mice exposed to irradiated schistosomes. Infect Immun 65: 42-48.

29. Arêas AP, Oliveira ML, Miyaji EN, Leite LC, Aires KA, et al. (2004) Expression and characterization of cholera toxin B-pneumococcal surface adhesin A fusion protein in Escherichia coli: ability of CTB-PsaA to induce humoral immune response in mice. Biochem Biophys Res Commun 321: 192-196.

30. Arêas AP, Oliveira ML, Miyaji EN, Leite LC, Ho PL (2005) Intraderma immunization of mice with cholera toxin B-pneumococcal surface protein A fusion protein is protective against intraperitoneal challenge with Streptococcus pneumonia. Infect Immun 73: 3810-3813.

31. Malley R, Morse SC, Leite LC, Areas AP, Ho PL, et al. (2004) Multiserotype protection of mice against pneumococcal colonization of the nasopharynx and middle nonencapsulated cells given intranasally with a nontoxic adjuvant. Infect Immun 72: 4290-4292.

32. Pimenta FC, Miyaji EN, Arêas AP, Oliveira ML, de Andrade AL, et al. (2006) Intranasal immunization with the cholera toxin B subunitpneumococcal surface antigen $\mathrm{A}$ fusion protein induces protection against colonization with Streptococcus pneumoniae and has negligible impact on the nasopharyngeal and oral microbiota of mice. Infect Immun 74: 4939-4944.

33. Dell K, Koesters R, Linnebacher M, Klein C, Gissmann L (2006) Intranasa immunization with human papillomavirus type 16 capsomeres in the presence of non-toxic cholera toxin-based adjuvants elicits increased vagina immunoglobulin levels. Vaccine 24: 2238-2247.

34. Kim HJ, Kim JK, Seo SB, Lee HJ, Kim HJ (2007) Intranasal vaccination with peptides and cholera toxin subunit B as adjuvant to enhance mucosal and systemic immunity to respiratory syncytial virus. Arch Pharm Res 30: 366-371.

35. Song H, Wang Z, Zheng D, Fang W, Li Y, et al. (2005) A novel mucosal vaccine against foot-and-mouth disease virus induces protection in mice and swine. Biotechnol Lett 27: 1669-1674.

36. George Chandy A, Hultkrantz S, Raghavan S, Czerkinsky C, et al. (2006) Oral tolerance induction by mucosal administration of cholera toxin B-coupled antigen involves T-cell proliferation in vivo and is not affected by depletion of CD25+ T cells. Immunology 118: 311-320.

37. Yuki Y, Hara-Yakoyama C, Guadiz AA, Udaka S, Kiyono H, et al. (2005) Production of a recombinant cholera toxin $B$ subunit-insulin $B$ chain peptide hybrid protein by Brevibacillus choshinensis expression system as a nasal vaccine against autoimmune diabetes. Biotechnol Bioeng 92: 803-809.

38. Sun JB, Li BL, Lakew M, Grzych JM, Capron A, et al. (2001) Nasal administration of Schistosoma mansoni egg antigens-cholera toxin B subunit conjugate to infected mice reduces immunopathology and mortality. Adv Exp Med Biol 495 305-309.

39. Sun JB, Stadecker MJ, Mielcarek N, Lakew M, Li BL, et al. (2001) Nasa administration of Schistosoma mansoni egg antigen-cholera B subunit conjugate suppresses hepatic granuloma formation and reduces mortality in $\mathrm{S}$. mansoniinfected mice. Scand J Immunol 54: 440-447. 